\section{International Journal of Medical Research and Review}

\title{
Clinico-radiological profile and outcome of patients undergoing intercostal tube drainage in a tertiary care hospital in West Bengal, India
}

\author{
Hassan M. ${ }^{1}$, Ghosh 5. ${ }^{2 *}$, Agarwalla A. ${ }^{3}$, Mandal A. ${ }^{4}$ \\ DOI: https://doi.org/10.17511/ijmrr.2019.i06.10 \\ 1 Md Ikbal Hassan, Senior Resident, Department of Respiratory Medicine, Malda Medical College, Malda, West Bengal, India. \\ 2* Saswata Ghosh, Associate Professor, Department of Respiratory Medicine, Malda Medical College, Malda, West Bengal, India. \\ ${ }^{3}$ Ajay Agarwalla, RMO, Department of Respiratory Medicine, Malda Medical College, Malda, West Bengal, India. \\ ${ }^{4}$ Animesh Mandal, Assistant Professor, Department of Respiratory Medicine, Malda Medical College, Malda, West Bengal, India.
}

Introduction: Evacuation of empyema which was first performed centuries ago, marked the beginning of thoracic drainage. The subsequent acquisition of a greater knowledge of the anatomy, physiology, and pathology of the pleural space directed the design of thoracic catheters and drainage systems and the development of the methods by which they are used. Thoracic drainage systems are designed to remove air and liquids from the pleural space or mediastinum, which collect there as a result of injury, disease, or surgical procedures. Method: A total of 100 patients who underwent intercostal tube drainage due to various etiologies are followed up for 3 months in the study Results: In this study it was observed that pneumothorax (67\%) as the most common indication for chest drain insertion followed by hydro-pneumothorax. During this period 100 patients of different pathologies related to chest underwent chest intubations. Amongst them 88 ( $88 \%)$ were male and $12(12 \%)$ were female. Subcutaneous emphysema was found to be the most common complication followed by ICD tube blockage. Among the study population 95\% patients were successfully treated $\&$ unsuccessful outcome was only $5 \%$. Conclusion: Chest tube insertion is a common procedure usually done for the purpose of draining accumulated air or fluid in the pleural cavity. Small-bore chest tubes $(\leq 14 \mathrm{~F})$ are generally recommended as the first-line therapy for spontaneous pneumothorax in non-ventilated patients and pleural effusions in general. Large-bore chest drains may be useful for very large air leaks, as well as post-ineffective trial with small-bore drains.

Keywords: Intercostal tube drainage, Pneumothorax, Empyema

Corresponding Author

Saswata Ghosh, Associate Professor, Department of Respiratory Medicine, Malda Medical College, Malda, West Bengal, India.

Email: drsaswata1969@gmail.com
How to Cite this Article

Hassan I, Ghosh S, Agarwalla A, Mandal A. Clinicoradiological profile and outcome of patients undergoing intercostal tube drainage in a tertiary care hospital in West Bengal, India. Int J Med Res Rev. 2019;7(6):504-510.

Available From

https://ijmrr.medresearch.in/index.php/ijmrr/article/ view/1109
To Browse

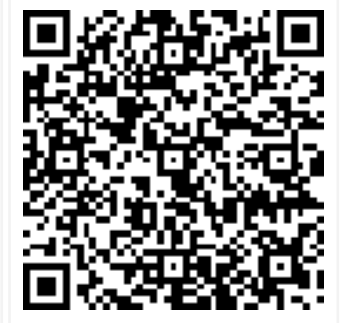

Manuscript Received 2019-11-26

Conflict of Interest No
Review Round 1 2019-12-06

Funding $\mathrm{Nil}$

Review Round 2
2019-12-10
Ethical Approval
Yes

Review Round 2 Yes
Review Round 3

Accepted 2019-12-14

Plagiarism X-checker $6 \%$

(c) 2019 by Md Ikbal Hassan, Saswata Ghosh, Ajay Agarwalla, Animesh Mandal and Published by Siddharth Health Research and Social Welfare Society. This is an Open Access article licensed under a Creative Commons Attribution 4.0 International License https://creativecommons.org/licenses/by/4.0/ unported [CC BY 4.0]. 


\section{Introduction}

Evacuation of empyema first performed centuries ago, marked the beginning of thoracic drainage. The subsequent acquisition of a greater knowledge of the anatomy, physiology, and pathology of the pleural space directed the design of thoracic catheters and drainage systems and the development of the methods by which they are used. Furthermore, a better understanding of the physics of vacuum and air flow brought about improvements in the use of suction with drainage.

Open drainage: Although it has its beginnings in antiquity, open thoracic drainage is still an integral part of the treatment of empyema or mediastinal infections. Methods of open drainage include the precise placement of a large tube or multiple tubes, segmental rib resection at a dependent site followed by the placement of large tubes [1] the occasional addition of sump drainage with or without irrigation [2], and open skin-pedicle drainage (Eloesser flap) [3].

Thoracic catheters: Chest tubes have witnessed their own evolution in course of time. Currently straight, right-angle, and trocar chest catheters as well as multichannel tubes for sump-irrigation drainage made of polyvinyl chloride, silicone elastomer, or silicone are available. Most have a radiopaque line, multiple inlet holes, and a flared end to allow for attachment to the drainage unit [4].

Thoracic drainage systems: The design of chest drainage systems must take into consideration the negative pressure (vacuum) of the pleural space created by the tendency of the elastic lungs to collapse, which is counterbalanced by the outward recoil of the chest wall. Normal intrapleural pressures are $-8 \mathrm{cmH} 20$ during inspiration and -3.4 $\mathrm{cm} \mathrm{H} 20$ during expiration. During forced inspiration (with a closed glottis or blocked endotracheal tube) and forced expiration (coughing), these pressures may reach extremes, exceeding $-54 \mathrm{~cm} \mathrm{H} 2 \mathrm{O}$ and $+70 \mathrm{~cm} \mathrm{H} 20$, respectively [5].

Management considerations: In recent years, numerous thorough discussions of chest drainage management have appeared in the literature [6]. Some subjects, because of their frequency of occur rence or seriousness, deserve particular emphasis. One of these is that too often the connecting tube is allowed to hang so that it drops below the top of the collection container and a resulting fluid-filled loop causes the suction drainage to stop.
Excess tubing should therefore be coiled on the bed and the tube should go straight from the patient to the collection system located on the floor. Fluid oscillations in the water seal synchronous with respiration (tidaling) confirm the presence of intrapleural pressures and tube patency. This motion stops when the lung is expanded or the system is blocked (clotting, kinking).

Suction: There was no agreement as to how much suction should be used. Some favored low suction $(-10 \mathrm{~cm} \mathrm{H} 20)$ [7] and others high suction $(-40 \mathrm{~cm}$ $\mathrm{H} 20$ ) [8]. The most common suction pressure is -20 $\mathrm{cm} \mathrm{H} 2 \mathrm{O}$.

\section{Aims \& Objectives}

01. To calculate the outcome of intercostal tube drainage in different disease process.

02. To assess the complication of intercostal tube drainage.

03. To determine the proportion of various cases requiring intervention by intercostal tube insertion.

\section{Materials and Methods}

Study area: Department of Respiratory Medicine in a tertiary care hospital in West Bengal.

Study population: Indoor patients in the Department of Respiratory Medicine underwent Intercostal Tube Drainage

Study period: 18 Months

\section{Inclusion criteria:}

01. All patients who underwent intercostal tube drainage of both sexes above 12 years of age.

02. Patient who gave written consent for the procedure.

03. All patients who have undergone Intercostal tube drainage and had been followed up in the OPD for at least 3month.

\section{Exclusion criteria}

01. Patients not giving consent to participate in the study.

02. Patient below 12 years of age

03. Traumatic pneumothorax,

04. Traumatic haemo-pneumothorax

05. Post thoracoscopy intercostal tube insertion

06. Ventilator associated pneumothorax 


\section{Sample size: 100}

Sampling design: As such no sampling technique has been adopted. All consecutive patients admitted in the department of Respiratory Medicine fulfilling the inclusion and exclusion criteria in the study were included.

Study design: Single centered Longitudinal Observational study.

Control: None

Method of data collection: After inclusion into this study, patients were evaluated as mentioned below-

01. Detailed history and clinical examination

02. Baseline investigations and other investigations as found necessary during the study mentioned below.

\section{Parameters of study}

01 . History including history of hospital admission in the previous one year.

02. Clinical examination- General Survey and Systemic examination

03. Investigations

- Baseline investigations

01. Blood for $\mathrm{Hb} \%$, total leucocyte count, differential leucocyte count, platelet count, ESR, fasting and postprandial glucose, urea, creatinine, liver function tests, electrolytes $(\mathrm{Na}+\mathrm{K}+\mathrm{Ca}+2)$. b) USG thorax c) Electrocardiogram in 12 leads

02. Blood for HIV $1 \& 2$ Antibodies, HbsAg, Anti HCV.

03. Sputum for AFB, Gram stain, pyogenic culture and sensitivity

04. Blood for Culture and sensitivity

05. Radiological investigations
a) Chest x-ray (PA view \& Lateral view) b) CECT Thorax (if required)

06. Pulse oximetry for $\mathrm{SpO} 2$

07. Pleural fluid analysis

08. $A B G$ analysis (if required)

The investigations may be repeated as per requirement based on clinical evaluation.

\section{Study tools}

01. a) Consent form b) Case record form c) Proforma for history taking including demographic details of the patient \& clinical examination including presence of comorbid conditions. d) Investigations (Blood, sputum , Pleural fluid, others...) e) ECG machine f) USG machine g) Chest $\mathrm{X}$-ray $\mathrm{h}$ ) CECT thorax i) Intercostal tube j) Water seal ICD Bag k) Pulse oximeter I.) ABG analyzer machine

Study technique- After taking approval from the Review Committee and the Institutional Ethics Committee all admitted patients meeting the inclusion and exclusion criteria and willing to give valid consent has been considered for study and subsequent evaluation.

Statistical analysis plan- Descriptive statistics was done by using Mean \& Standard Deviation and Frequency Distribution Tables and then inferential statistics was done according to what is needed.

\section{Results}

The present study was conducted at Department of Respiratory Medicine in a tertiary care hospital in West Bengal over a period of 18 months $A$ total of 100 patients who underwent Intercostal tube drainage due to various etiologies were followed up for 3 month and were enrolled in the study.

\section{Demographic Variables}

Table-1: Distribution of age.

\begin{tabular}{|l|l|l|l|l|l|}
\hline \multicolumn{1}{|c|}{ Age (years.) } & \multicolumn{1}{|c|}{ Pneumothorax } & Hydropneumothorax & Empyema & Malignant pleural effusion & Total \\
\hline $13-30$ years. & 47 & 11 & 2 & 0 & 60 \\
\hline $31-50$ years. & 16 & 5 & 7 & 1 & 29 \\
\hline$>50$ years. & 4 & 1 & 0 & 6 & 11 \\
\hline Total & 67 & 17 & 9 & 7 & 100 \\
\hline
\end{tabular}

Mean age was 32.66 years $S D \pm 13.59$; minimum age was 13 years and maximum age was 80 years. The most common age group was in the range of 13-30 years (Table 1 ).
The male to female ratio in the study group was 1.4 (Male -88 \& Female-22). Male to female ratio was 7.33: 1 (Table 2) 
Table-2: Gender distribution.

\begin{tabular}{|l|l|l|l|l|l|}
\hline \multicolumn{1}{|c|}{ Sex } & \multicolumn{1}{|c|}{ Pneumothorax } & \multicolumn{1}{c|}{ Hydropneumothorax } & Empyema & Malignant pleural effusion & Total \\
\hline Male & 62 & 15 & 7 & 4 & 88 \\
\hline Female & 5 & 2 & 2 & 3 & 12 \\
\hline Total & 67 & 17 & 9 & 7 & 100 \\
\hline
\end{tabular}

Table-3: Distribution of symptoms.

\begin{tabular}{|l|l|l|l|l|l|}
\hline \multicolumn{1}{|c|}{ Symptoms } & \multicolumn{1}{|c|}{ Pneumothorax } & Hydropneumothorax & Empyema & Malignant pleural effusion & Total \\
\hline SOB & 53 & 16 & 8 & 6 & 83 \\
\hline Chest pain & 61 & 17 & 9 & 7 & 94 \\
\hline Dry cough & 49 & 8 & 2 & 5 & 64 \\
\hline Productive cough & 6 & 7 & 5 & 2 & 20 \\
\hline Fever & 35 & 15 & 9 & 2 & 51 \\
\hline Haemoptysis & 2 & 0 & 7 & 7 & 7 \\
\hline Weight Loss & 5 & 4 & 9 & 7 & 23 \\
\hline Total & 67 & 17 & & & 100 \\
\hline
\end{tabular}

Most common symptoms among the pneumothorax patient were dry cough $(p=0.004, r=0.271)$ \& shortness of breath (SOB). Hydropneumothorax patients mostly presented with SOB \& productive cough $(p+0.091)$, Empyema mostly presented with productive cough $(p=0.0128, r=0.279)$ with significant weight $\operatorname{loss}(p=0.0003, r=0.409)$ and malignant pleural effusion mainly presented with weight loss $(p<0.05, r=0.501)$, haemoptysis $(p<0.05, r=0.692)$, sob \& chest pain (Table 3$)$.

\begin{tabular}{|l|l|l|l|}
\hline Pleural fluid study & Hydropneumothorax & Empyema & Total \\
\hline Tubercular & 9 & 2 & 11 \\
\hline Bacterial & 8 & 7 & 15 \\
\hline Total & 17 & 9 & 26 \\
\hline
\end{tabular}

\section{Table-4: Distribution of diagnostic pleural fluid}

Pleural fluid helps in the aetiological diagnosis of hydropneumothorax \& empyema -

01. a) Hydropneumothorax: 1. Tubercular $(p<0.05$, $r=0.6062 ; 2$. Bacterial $(p<0.05, r=0.406)$,

02. b) Empyema: 1. Tubercular $(p<0.05, r=0.55)$; 2. Bacterial $(p<0.05, r 0.552)$ (Table 4$)$.

Table-5: Distribution of sputum for AFB positive patients.

\begin{tabular}{|l|l|l|l|l|l|}
\hline & \multicolumn{1}{|c|}{ Pneumothorax } & Hydropneu- mothorax & Empyema & \multicolumn{1}{|c|}{ Malignant pleural effusion } & Total \\
\hline Sputum AFB under RNTCP & 27 & 5 & 1 & 0 & 33 \\
\hline Total & 67 & 17 & 9 & 7 & 100 \\
\hline
\end{tabular}

Sputum for AFB under RNTCP are mostly positive for the pneumothorax $(p=0.015, r=0.221)$ patients \& the data is statistically significant (Table 5).

Table-6: Distribution of sputum pyogenic culture positive results.

\begin{tabular}{|l|l|l|l|l|l|}
\hline & \multicolumn{1}{|c|}{ Pneumothorax } & \multicolumn{1}{|c|}{ Hydropneumothorax } & Empyema & \multicolumn{1}{|c|}{ Malignant pleural effusion } & Total \\
\hline Sputum pyogenic culture positive & $17(25.3 \%)$ & $5(29.4 \%)$ & $2(22.2 \%)$ & 0 & 24 \\
\hline Total & 67 & 17 & 9 & 7 & 100 \\
\hline
\end{tabular}

In this study population it was observed that $25.3 \%$ patients out of total pneumothorax, $29.4 \%$ patients of the hydropneumothorax $\& 22.2 \%$ of the empyema patients were positive for pyogenic C/S (Table 6).

Table-7: Distribution of complications.

\begin{tabular}{|l|l|l|l|l|l|}
\hline \multicolumn{1}{|c|}{ Complications } & \multicolumn{1}{|c|}{ Pneumothorax } & Hydropneumothorax & Empyema & Malignant pleural effusion & Total \\
\hline ICD Tube blockage & 11 & 3 & 2 & 0 & 16 \\
\hline Lung Injury & 3 & 1 & 0 & 0 & 4 \\
\hline Haematoma & 2 & 0 & 0 & 0 & 2 \\
\hline Subcutaneous Emphysema & 17 & 2 & 0 & 0 & 19 \\
\hline
\end{tabular}


Among the complication related to Intercostal tube drainage Subcutaneous emphysema is most common and it occurred in pneumothorax
$(P=0.013, \quad r=0.231)$ followed by hydropneumothorax patients. Second most common complication was ICD tube blockage (Table 5).

Table-8: Distribution of Outcome of intercostal tube drainage.

\begin{tabular}{|l|l|l|l|l|l|}
\hline \multicolumn{1}{|c|}{ Outcome } & \multicolumn{1}{|c|}{ Pneumothorax } & Hydropneumothorax & Empyema & Malignant pleural effusion & Total \\
\hline Self-expulsion of ICD tube & 0 & 0 & 2 & 1 & 3 \\
\hline Patient successfully treated & 64 & 16 & 8 & 7 & 95 \\
\hline Unsuccessful outcome & 3 & 1 & 1 & 0 & 5 \\
\hline Total & 67 & 17 & 9 & 7 & 100 \\
\hline
\end{tabular}

Self-expulsion of the ICD tube occurs mostly in the patient of Empyema $(p=0.02, r=0.354) \&$ in all 3 cases, self-expulsion of the ICD tube occurs after complete expansion of the lung. Among the study population $95 \%$ patient successfully treated \& unsuccessful outcome was only $5 \%$.
Unsuccessful outcomes were mostly due to persistent bronchopulmonary fistula (BPF)\& associate co-morbid condition of the patient. Unsuccessful outcome may be overcome by early Cardiothoracic intervention (Table 8).

Table-9: The p-Values (p).

\begin{tabular}{|l|l|l|l|l|}
\hline \multicolumn{1}{|c|}{ Outcome } & \multicolumn{1}{|c|}{ Pneumothorax } & \multicolumn{1}{|c|}{ Hydropneumothorax } & \multicolumn{1}{c|}{ Empyema } & \multicolumn{1}{|c|}{ Malignant pleural effusion } \\
\hline Self-Expulsion of ICD tube & 0.033741497 & 0.568218924 & 0.0202597 & 0.185194805 \\
\hline Patient successfully treated & 0.335963251 & 0.414936499 & 0.3194956 & 0.69030409 \\
\hline Unsuccessful outcome & 0.335963251 & 0.414936499 & 0.3194956 & 0.69030409 \\
\hline
\end{tabular}

\section{Discussion}

Chest tube insertion is the commonly performed procedure throughout the world. In this study the indications, complications and outcome of tube thoracostomy performed by Pulmonologist are evaluated. In this study, it was observed that pneumothorax $(67 \%)$ as most common indication for chest drain insertion. Other indications for tube thoracostomy in this study were hydropneumothorax (17\%), empyema /parapneumonic effusion (9\%) \& malignant pleural effusion (7\%). Aylwin CJ et al [9] and Miller KS et al [10] in two different studies showed that the most frequent indication for tube thoracostomy was for malignant/paramalignant effusion, 46 (27.5\%), Others were trauma $44(26.3 \%)$, parapneumonic effusion $20(12 \%)$, post thoracotomy $14(8.4 \%)$, empyema thoracis $12(7.2 \%)$, heart disease and tuberculous effusion $11(6.6 \%)$, pneumothorax 8 $(4.8 \%)$ these data are quite different from the present study.

During this period 100 patients of different pathologies related to chest underwent chest intubations. Mean age was 32.66 years SD \pm 13.59 ; minimum 13 years and max. 80 years.
Amongst them $88(88 \%)$ were male and $12(12 \%)$ were female. Male to female ratio was7.33: 1. Right-sided procedure was performed in $65(65 \%)$ patients and left tube thoracostomy in $35(35 \%)$ patients. Most common symptoms among the pneumothorax patient are dry $\operatorname{cough}(p=0.004, r=0.271)$ \& shortness of breath.. Hydropneumothorax mostly present with shortness of breath \& productive cough $(p=0.091)$, Empyema mostly present with productive cough $(p=0.0128$, $r=0.279)$ with significant weight loss ( $p=0.0003$, $r=0.409)$ \& Malignant pleural effusion mainly presents with weight loss $(p<0.05, r=0.501)$, hemoptysis $(p<0.05, r=0.692)$, shortness of breath $\&$ chest pain. Diabetic patients are prone to developed empyema $(p=0.004)$.

Among the patient who underwent ICD drainage there was a past history of Pulmonary TB in pneumothorax, hydropneumothorax empyema were $81 \%, 14 \%, 5 \%$ respectively. There high chance of developing empyema among the alcoholic $(p=0.0008, r=0.398)$ patients \& there is strong correlation. Tall \& thin built $(p<0.05$, $r=0.573$ ) patient are more prone to developed Pneumothorax \& there is a strong correlation with the disease. 
Poor nutritional status $(0.019, r=0.225)$ patient are mostly associated with empyema. Palpable lymph node $(p<0.05, r=0.692) \&$ clubbing $(p<0.05$, $r=0.501$ ) is mostly associated with malignant pleural effusion. Among the patient of Pneumothorax, primary spontaneous pneumothorax mostly associated with tall \& thin built person $(p<0.05, r=0.526)$ whereas is secondary pneumothorax patient commonly associated with sputum positive for AFB $(p<0.05, r=0.703)$ pulmonary tuberculosis. Collop NA et al [11] revealed incidence rate of Spontaneous Pneumothorax was $2.30 \%$ among the chest symptomatic patients, above the 15 years of age population.

Pulmonary tuberculosis is the main etiological factor of Spontaneous Pneumothorax in India. In this study it was observed that Contralateral mediastinal shift is associated with pneumothorax $(p=0.001, r=0.320)$ hydropneumothorax $(p<0.039)$. With help of Chest $X$-ray alone Pneumothorax $(p<0.05, r=0.621)$ hydropneumothorax $(p=0.038, r=0.197)$ can be diagnosed $[11,12,13]$. almost all the patients showed ECG changes (ischemic changes, tachycardia, arrhythmia) commonly encountered in Pneumothorax (19.4\%) patients. In the present study, it was observed that $\mathrm{Spo} 2<88 \%$ is more common in the patients of malignant pleural effusion $(p=0.048, r=0.228))$ with shortness of breath. Pleural fluid helps in the aetiological diagnosis of a) Hydropneumothorax 1 . Tubercular $(p<0.05, r=0.60) ; 2$. Bacterial $(p<0.05, r=0.40), b)$ Empyema

1.Tubercular $(p<0.05, r=0.55) ; 2$. Bacterial $(p<0.05$, r0.55) \&c) Malignant pleural effusion ( $p<0.05, r=1)$. CECT thorax helps in the diagnosis of the encysted lesion \& underlying lung pathology. It helps mostly detecting the underlying lung pathology for malignant pleural effusion $(n=0.01 ; r=0.28)$ as well as for empyema $(p<0.05 ; r=0.45)$ This matches with the result done by Aylwin $\mathrm{C}$ ] et al [9]. Anemia most commonly seen in empyema $(p<0.05, r=0.377)$ \& malignant pleural effusion $(p=0.001, r=0.329)$ patients; in both cases the data are statistically significant. Leucocytosis is commonly associated with bacterial hydropneumothorax $(p<0.05)$ \& Empyema $(p<0.05, r=0.338)$. Sputum for AFB under RNTCP are mostly positive for the pneumothorax $(p=0.015, r=0.221)$ patients \& the data is statistically significant \& has strong correlation.
Radiological pathology in the opposite lung seen mostly in the case of Pneumothorax. Being an invasive procedure intercostals tube insertion into the chest is associated with potential complications. Some of these complications are minor in nature and required minimal further intervention. Various types of complications encountered in 41patients; among the complication related with Intercostal tube drainage.

Subcutaneous emphysema is most common and it occurred in pneumothorax $(p=0.013, r=0.231)$ followed by hydropneumothorax patients \& it resolved spontaneously within few days. Second most common complication was ICD tube blockage. In different studies by Maritz $D$ et al [15], Omar HR et al [16] and Baldt $M$ et al [17], they found subcutaneous emphysema was found in $19 \%$ patients which is quite similar to the present study. Al- Tarshihi MI et al [18] observed overall complication rate of $16.8 \%$ which is much less than the present study. In the present study, no diaphragmatic injury was noted. This injury can be avoided by putting the chest tubes in intercostal space not lower than the 4th space as diaphragm may move up to 5th intercostal space during expiration83. Self-expulsion of the ICD tube occurs mostly in the patient of empyema $(p=0.02$, $r=0.354)$.

Among the study population recurrent Intercostal tube given in $7.46 \%$ of pneumothorax cases \& $5.88 \%$ of the hydropneumothorax cases. Among the total encysted lesion most encystment found in pneumothorax patient followed by hydropneumothorax \& empyema patients. There was total 6 recurrent ICD insertion cases among them 5 patients was recurrent pneumothorax \& 1 hydropneumothorax case.

There were 2 cases of pneumothorax who underwent $B / L \quad I C D$ insertion, 1 case of hydropneumothorax who underwent $B / L$ ICD insertion. Self-expulsion of the ICD tube occurs mostly in the patient of Empyema $(p=0.02$, $r=0.354) \&$ in all these cases, self-expulsion of the ICD tube occurs after complete expansion of the lung. Among the study population 95\% patient successfully treated \& unsuccessful outcome was only $5 \%$. Unsuccessful outcome may be overcome by early cardiothoracic intervention.

The mean duration of ICD in-situ for Pneumothorax is $(17.26 \pm 8.1)$ days, Hydropneumothorax (22.35 \pm 5.84$)$ days; Empyema (35.71 \pm 5.85$)$ days; 
\& Malignant pleural effusion (25.5 \pm 4.37$)$ days.

One of empyema \& one of the malignant pleural effusion patient ICD could not be omitted between 3 month of follow-up period. However, in this study all patients with malignant effusion secondary to malignancy and required chest drain insertion was referred to oncologist for further management.

\section{Limitations}

01. Inability to perform pleurodesis in cases with recurrent pneumothorax and in malignant diseases.

02. Non-availability of specialized thoracic surgery units where specialized procedures thoracotomy can be performed

03. Among the empyema patients who underwent intercostal tube drainage one of them ICD could not be removed within the 3month of follow-up.

04. Among the pneumothorax patients who underwent intercostal tube drainage three of them ICD could not be removed within the 3month of follow-up.

05. Among the hydro-pneumothorax patients who underwent intercostal tube drainage, ICD could not be removed from one of them within the 3month of follow-up.

\section{Conclusion}

Chest tube insertion is a common procedure usually done for the purpose of draining accumulated air or fluid in the pleural cavity. Small-bore chest tubes $(\leq 14 \mathrm{~F})$ are generally recommended as the first-line therapy for spontaneous pneumothorax in nonventilated patients and pleural effusions in general.

Large-bore chest drains may be useful for very large air leaks, as well as post-ineffective trial with smallbore drains. Chest tube insertion should be guided by imaging, either bedside ultrasonography or, less commonly, computed tomography.

\section{What the study adds to the existing knowledge?}

Most procedures consist of the US-guided insertion of LBCT (large bore chest tube) with the Seldinger technique in patients with pneumothorax is, complicated parapneumonic effusions /empyemas, or malignant pleural effusions. The so-called trocar technique must be avoided.
Instead, blunt dissection (for tubes $>24 \mathrm{~F}$ ) or the Seldinger technique should be used. All chest tubes are connected to a drainage system device: underwater seal, electronic systems or, for indwelling pleural catheter (IPC), vacuum bottles. The optimal timing for tube removal of intercostal tube depends on the various disease processes as well as treatment of underlying etiology.

Subcutaneous emphysema, ICD tube blockage, local hematoma and accidental dislodgement are common complications of small-bore drains; Pulmonologists should be familiar with the common complications that may occur during or after chest tube insertion, some of which are potentially dangerous (e.g., malposition, haemothorax, infection, organ injury, or re-expansion pulmonary edema.

\section{Author's contribution}

Dr. Md Ikbal Hassan: Concept designing, conducting the study, performing the procedures and following up the patients.

Dr. Saswata Ghosh: Guided the study procedure and preparing the manuscript suitable for publication.

Dr.Ajay Agarwalla and Dr. Animesh Mandal: Conducted the study.

\section{Reference}

01. Emergency Nurses Association. Trauma nursing core course (Instructor Supplement). 5th ed. 2000;63-72,278-282.

[Crossref]

02. Emergency Nurses Association. Course in advanced trauma nursing-II- A conceptual approach to injury and illness (Student Manual). 2nd ed. 2003;39-59.

[Crossref]

03. Ganong, WF. Review of medical physiology. New York, NY- McGraw Hill Medical Publishing Division, 20th ed. 2001;644-673.

[Crossref]

04. Kapit W, Elson LM. Anatomy coloring book. New York, NY- HarperCollins Publishers, 2nd ed. 2003;91-97.

[Crossref]

05. Marino, PL. The ICU book. Baltimore, PAWilliams \& Wilkins, 2nd ed. 1998;459-62.

[Crossref] 
06. Parsons PE, Heffner JE. Pulmonary/Respiratory therapy secrets. Philadelphia, PA- Hanley \& Belfus, Inc, 2nd ed. 2002;68-73.

[Crossref]

07. Millikan J, Moore E, Steiner E, Aragon GE, Van Way CW. Complications of tube thoracostomy for acute trauma. Am J Surg. 1980;140(6)738741.

doi: $10.1016 / 0002-9610(80) 90107-5 \quad$ [Crossref]

08. Collop NA, Kim S, Sahn SA. Analysis of tube thoracostomy performed by pulmonologists at a teaching hospital. Chest. 1997;112(3)709-713. doi: $10.1378 /$ chest.112.3.709 [Crossref]

09. Aylwin CJ, Brohi K, Davies GD, Walsh MS. Prehospital and In- Hospital ThoracostomyIndications and complications. Ann R Coll Surg Eng. 2008;90(1)54-57.

doi: $10.1308 / 003588408 \times 242286 \quad$ [Crossref]

10. Miller KS, Sahn SA. Review, Chest tubesIndications, technique, management and complications. Chest. 1987;91(2)258-264.

doi: $10.1378 /$ chest. 91.2.258 [Crossref]

11. Dural K, Gulbahar G, Kocer B, Sakinci U. A novel and safe technique in closed tube thoracostomy. J Cardiothorac Surg. 2010;5;21.

doi: 10.1186/1749-8090-5-21 [Crossref]

12. Maritz D, Wallis L, Hardcastle T. Complications of tube thoracostomy for chest trauma. S Afr Med J. 2009;99(2)114-117.

[Crossref]
13. Bailey RC. Complications of tube thoracostomy in trauma. J Accid Emerg Med. 2000;17(2)111114.

doi: 10.1136/emj.17.2.111 [Crossref]

14. Etoch SW, Bar-Natan MF, Miller FB, et al. Tube thoracostomy-factors related to complications. Arch Surg. 1995;130(5)521-526.

doi: $\quad$ 10.1001/archsurg.1995.01430050071012 [Crossref]

15. Stark D, Federle M, Goodman P. CT and radiographic assessment of tube thoracostomy. AJR. 1983;141(2)253-258.

doi: 10.2214/ajr.141.2.253 [Crossref]

16. Omar HR, Abdelmalak H, Mangar D, Rashad R, Helal E, Camporesi EM. Occult pneumothorax, revisited. J Trauma Manag Outcomes. $2010 ; 4 ; 12$.

doi: $10.1186 / 1752-2897-4-12$ [Crossref]

17. Baldt M, Bankier A, Germann P, Poschl GP, Skrbensky GT, Herold CJ. Complications after emergency tube thoracostomy- assessment with CT. Radiol. 1995;195(2)539-543.

doi: 10.1148/radiology.195.2.7724780 [Crossref]

18. Al- Tarshihi MI, Khamash FA, Al-Ibrahim AEO. Thoracostomy complications and pitfalls- An experience at tertiary care military hospital. Rawal Med J. 2008;33(2)141-144.

[Crossref] 